\title{
Utilização do teste de eritroimunoadsorção por captura no imunodiagnóstico da neurocisticercose*
}

\author{
Capture erytroimmunoadsorption test for neurocysticercosis immunodiagnosis
}

\author{
Carmen Silvia de M. Pialarissi ${ }^{\star \star \star}$, Sandra Maria Ottati de Oliveira Nitrini ${ }^{\star \star}$
}

\begin{abstract}
PIALARISSI, C.S. de M. \& NITRINI, S.M.O. de O. Utilização do teste de eritroimunoadsorção por captura no imunodiagnóstico da neurocisticercose. Rev. Saúcle Pública, 28: 116-20, 1994. Foi padronizado o teste de eritroimunoadsorção por captura (ELC) para detecção de anticorpos específicos anti-cisticercos de Taenia solium, classe IgG, no líquido cefalorraquidiano (LCR) de pacientes com neurocisticercose. O reagente empregado para detecção de anticorpos específicos foi preparado com hemácias de carneiro em uma concentração de 0,25\%, sensibilizadas com antígeno extrato salino bruto (ESB) obtido do Cysticercus cellulosae. A concentração ótima de ESB para sensibilização das hemácias de carneiro foi de $40 \mathrm{ug} / \mathrm{ml}$. O rendimento do ESB foi de 0,lug proteína/cavidade. $A$ sensibilidade do teste foi de $84,5 \%$ (limite de confiança $95 \%$ de $75 \%$ a $94 \%$ ), quando aplicado a 58 amostras de LCR de pacicntes com neurocisticercose; a especificidade foi de $95,3 \%$ (limite de confiança 95\% de 90,7\% a 99,9\%) quando 85 amostras de LCR do grupo controle foram analisadas. O teste ELAC foi eficiente para o diagnóstico da neurocisticercose, e é importante para os laboratórios de saúde pública, tendo cm vista a fácil execução, alto rendimento e baixo custo.
\end{abstract}

Descritores: Cisticercose, diagnóstico. Técnicas de imunoadsorção. Anticorpos anti-helmintos, lesões.

\section{Introdução}

A neurocisticercose é uma infecção do sistema nervoso central causada pela larva da Taenia solium, constituindo problema de saúde pública, principalmente nos países em desenvolvimento, na medida em que as deficientes condições de saneamento ambiental e de educação sanitária estão diretamente envolvidas em sua endemicidade.

A prevalência da neurocisticercose no Brasil não é bem definida pois não existem inquéritos populacionais sistemáticos. Portanto, estudos soroepidemiológicos são importantes para avaliar os casos de infecção e os casos-contactantes na população em geral. Apesar da escassez de dados, alguns autores utilizaram reações sorológicas tais como: reação de fixação de

- Resumo da Dissertação de Mestrado apresentada à Faculdade de Saúde Pública da USP - 1992.

* Departamento de Prática de Saúde Pública da Faculdade de Saúde Pública da Universidade de São Paulo - São Paulo, SP - Brasil

*** Instituto Adolfo Lutz - São Paulo, SP - Brasil

Separatas/Reprints: C.S. de M. Pialarissi - Av. Dr. Arnaldo, 351 - 01246-902 - São Paulo, SP - Brasil

Edição subvencionada pela FAPESP. Processo 94/0500-0 complemento, hemaglutinação passiva e ELISA para o diagnóstico da neurocisticerco$\mathrm{se}^{1,2,4,10,12,19,15,18,19}$

A padronização de um novo teste para o diagnóstico da inlecção, exeqüível nas condições de um laboratório de saúde pública, vem de encontro à necessidade atual de se acrescentar à rotina diagnóstica métodos de maior praticidade e cficićncia com sensibilidade e especificidade adequadas às suas finalidades.

$O$ presente trabalho tcm por objetivo a padronização de um teste simples para imunodiagnóstico da neurocisticercose, cujo princípio é a modificação de um teste de hemaglutinação passiva, de baixo custo, para ser utilizado principalmente em laboratórios de saúde pública.

\section{Material e Métodos}

\section{Amostras de liquido cefalorraquidiano (LCR)}

Foram coletadas amostras de LCR de 143 pacientes e conservadas a $-20^{\circ} \mathrm{C}$ até o momento de uso. As amostras foram classificadas em três 
grupos: grupo D $=58$ amostras de LCR de pacientes com neurocisticercose, diagnosticados segundo dados clínicos, epidemiológicos e laboratoriais, ou seja, pacientes com hipertensão intracraniana ou epilepsia ou ambas, neuroimagem compativel com neurocisticercose e LCR com características inflamatórias e com anticorpos específicos; grupo $S=37$ amostras de LCR de indivíduos supostamente não-doentes, com quimiocitológico normal colhidas por ocasião de raquianestesias ou para controle de alta hospitalar após infecções agudas de sistema nervoso; grupo $\mathrm{E}=\mathbf{4 8}$ amostras de LCR de pacientes com encefalopatias de diferentes etiologias, que não fossem portadores de neurocisticercose.

\section{Antigeno e reagentes}

$O$ antígeno utilizado foi o extrato salino bruto (ESB) de cisticercos, obtido segundo a metodologia descrita por $\operatorname{Costa}^{6}(1983)$ e cmpregada com modificações por Vaz e Ferreira ${ }^{17}$ (1988).

O ESB foi utilizado no preparo do reagente de hemácias sensibilizadas. Estas foram obtidas utilizando-se hemácias de carneiro fixadas por glutaraldeido ${ }^{3}$ e sensibilizadas com o antígeno ESB, segundo a técnica de Imai e col. ${ }^{9}$ (1974). A solução estabilizadora das hemácias consistiu de: leite desnatado $0,3 \%(\mathrm{p} / \mathrm{v})$ em solução fisiológica tamponada com fosfato $0,0375 \mathrm{M}, \mathrm{pH}=$ $6,4^{16}$.

A determinação protéica do antígeno foi feita segundo o método de Bradford ${ }^{5}$ (1976).

\section{Padronização da técnica (EIAC)}

A técnica padronizada obedeceu o seguinte protocolo:

- as placas de microtitulação foram sensibilizadas com soro de coelho anti-IgG humana diluída a 1:1600 (Dakopatts-Dinamarca), em solução tamponada com carbonato-bicarbonato $0,05 \mathrm{M}, \mathrm{pH}=9,6$, no volume de $0,1 \mathrm{ml}$ por cavidade;

- incubação por 60 min à tempcratura ambiente e por $18 \mathrm{~h} \mathrm{a} 4^{\circ} \mathrm{C}$;

- lavagem das placas com solução de lavagem (SST-T), solução fisiológica tamponada com fosfato $0,01 \mathrm{M} \mathrm{pH}=7,4$ adicionada de tween 20 a $0,05 \%$ ) por três vezes;

- aplicação da amostra de LCR em volume de $0,1 \mathrm{ml} \mathrm{cm}$ uma coluna da placa, para as hemácias sensibilizadas, e o mesmo volume na coluna seguinte para as hemácias-controle, com a amostra pura e em diluição subseqüente na razão 2 ;

- incubação por 60 min à temperatura ambiente; lavagem das placas com solução de lavagem (SST-T), por três vezes;

- aplicação das hemácias sensibilizadas e das hemácias-controle, em concentração de $0,25 \%(\mathrm{v} / \mathrm{v}) \mathrm{e} \mathrm{em}$ volume de $0,05 \mathrm{ml}$ por cavidade, nas respectivas colunas da placa;

- incubação $\mathrm{cm}$ câmara úmida por $90 \mathrm{~min}$ $\left(20-25^{\circ} \mathrm{C}\right)$

- leitura da reação.

\section{Análise estatística}

Foram utilizados os scguintes testes: reprodutibilidade inter-teste e intra-teste, bem como a reprodutibilidade entre diferentes lotes de hemácias frente ao LCR-padrão (diagrama de controle de qualidade, segundo Hoshino-Shimizu e col. ${ }^{8}$ (1986); média geométrica dos títulos (MGT) calculada de acordo com Paul \& White ${ }^{11}$ (1973). Utilizou-se o método do qui quadrado para se verificar o nível de associação, adotando-se para $\alpha$, o nível de $1 \%$ de erro; o desempenho do método foi analisado mediante a determinação da sensibilidade, especificidade, eficiência, valor preditivo positivo e negativo, e os limites de confiança foram estabelecidos ao nível de $95 \%^{7,13}$.

\section{Resultados}

A determinação da concentração protéica final clo antígeno resultou $\mathrm{em} 2,6 \mathrm{mg}$ de proteína por $\mathrm{ml}$.

A concentração de $40 \mathrm{ug} / \mathrm{ml}$ foi escolhida para sensibilizar os eritrócitos de carneiro na pesquisa de anticorpos anti-cisticercos de Taenia solium pelo teste de eritroimunoadsorção por captura, por fornecer reatividade máxima com o ICR-padrão positivo, sem contudo apresentar reação inespecífica com o LCR-padrão negativo (Tabela 1). 
Tabela 1 - Títulos obtidos com LCR-padrão em função da concentraçāo protéica do antígeno ESB, no teste de eritroimunoadsorção por captura, para avaliação de anticorpos da neurocisticercose.

\begin{tabular}{ccc}
\hline $\begin{array}{c}\text { ESB Concentração } \\
\text { Protéica }(u \mathrm{~g} / \mathrm{ml})\end{array}$ & $\begin{array}{c}\text { LCR Padrão } \\
\text { Positivo }\end{array}$ & $\begin{array}{c}\text { LCR Padrão } \\
\text { Negativo }\end{array}$ \\
\hline 100 & NR & NR \\
60 & 32 & NR \\
10 & 1.024 & NR \\
30 & 1.024 & NR \\
20 & 256 & NR \\
5 & NR & NR \\
\hline
\end{tabular}

LCR - Líquido Cefalorraquidiano

ESB - Extrato Salino Bruto

NR - Não Reagente

A avaliação da reprodutibilidade intra-teste foi realizada com os resultados de 10 amostras de LCR positivas $\mathrm{c}$ as $10 \mathrm{de}$ LCR negativas, $\mathrm{cm}$ 5 replicatas. $O$ desvio-padrão (DP) variou cntre 0 e 0,58 .

A reprodutibilidadc inter-teste também foi avaliada com 10 amostras positivas e 10 negativas em dois dias consccutivos, com um desviopadrĩo de 0,58 e 0,67 .

O I.CR-padrão positivo foi analisado com difcrentes loles de hemácias, $\mathrm{cm} 20$ dias e o título variou entre 512 e 1.096 . O desvio-padrão médio foi de $1,08 \mathrm{c}$ o limite de accitação foi de 1,16. O limite de accitação foi calculado multiplicando-se por 2 o desvio-padrão obtido em ensaio cujo reagente foi considerado adequado.

$\Lambda$ clistribuição das 143 amostras de LCR de acordo com títulos obtidos no teste de eritroimunoadsorção por captura (LLAC) é apresentada na Tabcla 2.

Os títulos obtidos nas 58 amostras do grupo de cstudos (D) oscilaram cntre 2 a 8.192, com média gcométrica (MG'I) de 131,21. $\Lambda$ MGT do grupo $S$ foi 1 e no grupo $L, 1,28$.

Os resultados com título igual ou superior a 4 foram considcrados significativos, pois o limiar de rcatividacle ("cut ofl") ighual a 1:4 foi obtido pelo cálculo da média do grupo controle (S e E) mais dois desvios-padrão $(x+2 D P)$. Segundo este

Tabela 2 - Número e percentagem de individuos, segundo grupos (doentes, não doentes $\theta$ com encefalopatias) e títulos de EIAC para neurocisticercose

\begin{tabular}{|c|c|c|c|c|c|c|c|c|}
\hline \multirow[t]{2}{*}{ Títulos } & \multicolumn{2}{|c|}{$\begin{array}{l}\text { Doentes } \\
\text { (D) }\end{array}$} & \multicolumn{2}{|c|}{$\begin{array}{l}\text { Não Doentes } \\
\text { (S) }\end{array}$} & \multicolumn{2}{|c|}{$\begin{array}{c}\text { C/ Encefalopatias } \\
\text { (E) }\end{array}$} & \multicolumn{2}{|c|}{ Total } \\
\hline & № & $\%^{\circ}$ & $\mathrm{N}^{2}$ & $\%^{\circ}$ & № & $\%^{\circ}$ & № & $\%^{*}$ \\
\hline NR & 7 & 12,1 & 37 & 100,0 & 35 & 72,9 & 79 & 55,2 \\
\hline 1 & - & - & - & - & - & - & - & - \\
\hline 2 & 2 & 3,4 & - & - & 9 & 18,7 & 11 & 7,7 \\
\hline 4 & 3 & 5,2 & - & - & 4 & 8,3 & 7 & 4,9 \\
\hline 8 & 1 & 1,7 & - & - & - & - & 1 & 0,7 \\
\hline 16 & 3 & 5,2 & - & - & - & - & 3 & 2,1 \\
\hline 32 & 1 & 1,7 & - & - & - & - & 1 & 0,7 \\
\hline 64 & 3 & 5,2 & - & - & - & - & 3 & 2,1 \\
\hline 128 & 4 & 6,9 & - & - & - & - & 4 & 2,8 \\
\hline 256 & 7 & 12,0 & - & - & - & - & 7 & 4,9 \\
\hline 512 & 6 & 10,3 & - & - & - & - & 6 & 4,2 \\
\hline 1.024 & 10 & 17,2 & - & - & - & - & 10 & 7,0 \\
\hline 2.048 & 7 & 12,1 & - & - & - & - & 7 & 4,9 \\
\hline 4.096 & 3 & 5,2 & - & - & - & - & 3 & 2,1 \\
\hline 8.192 & 1 & 1,7 & - & - & - & - & 1 & 0,7 \\
\hline Total & 58 & 100,0 & 37 & 100,0 & 48 & 100,0 & 143 & 100,0 \\
\hline
\end{tabular}

EIAC - Eritroimunoadsorção por captura

- As percentagens foram calculadas em relação ao total de cada grupo: D, S e E 
Tabela 3. Distribuição dos pacientes do grupo de estudo (D) e do grupo controle (S e E) quanto aos resultados no LCR pelo teste EIAC.

\begin{tabular}{|c|c|c|c|c|c|}
\hline \multirow[t]{2}{*}{ EIAC } & \multicolumn{2}{|c|}{$\begin{array}{l}\text { Doentes } \\
\text { (D) }\end{array}$} & \multicolumn{2}{|c|}{$\begin{array}{l}\text { Controle } \\
(S+E)\end{array}$} & \multirow[t]{2}{*}{ Total } \\
\hline & $\mathrm{N}$ & $\%$ & $N$ & $\%$ & \\
\hline Positivo & 49 & 84,5 & 4 & 4,7 & 53 \\
\hline Negativo & 9 & $\{5,5$ & 81 & 95,3 & 90 \\
\hline Total & 58 & 100,0 & 85 & 100,0 & 143 \\
\hline
\end{tabular}

LCR - Liquido Cefalorraquidiano

EIAC - Teste de eritroimunoadsorção por captura

critério, os resultados interpretados como positivos no grupo de doentes totalizaram $84,5 \%$ conforme sc verifica pela Tabcla 3. Houve uma diferença estatisticamentc significantc $(x=$ $90,68) \mathrm{cm}$ relação ao grupo controlc $(S+\mathrm{E}) \mathrm{com}$ $\mathrm{p}<0,001$.

A sensibilidacte diagnóstica do teste liLC obtida nas condiçócs padronizadas foi de $84,5 \%$, com limite de confiança de $95 \%$ c intervalos de confiança de $75 \%-9 \%$.

$\Lambda$ especificidade do leste EI $\Lambda$ C foi de 95,3\%, com limite de confiança de $95 \%$ e intervalo de confiança de $90,7 \%-99,9 \%$.

O valor preditivo positivo foi de $92,5 \% \mathrm{e} \mathrm{o}$ valor preditivo negativo foi de $90,0 \%$ para a prevalência estudada de $10,6 \%$. $\Lambda$ cficiência do teste foi de $90,9 \%$ nas condições empregadas.

\section{Discussão}

Durante o processo de paclronização, algumas variáveis foram importantes lais como temperatura da reaçĩo, tempo de leitura, concentração de hemácias de carnciro no reagente preparado e principalmentc a solução estabilizadora de homácias, cuja concentração de leite desnatado e molaridade de solução tampão permitiram a estabilidade de reação, conforme já havia demonstrado Uedial ${ }^{16}$ (1988).

A concentração de $10 \mathrm{ug} / \mathrm{ml} \mathrm{cm}$ protcína do ESB, utilizada para scnsibilizar as hemácias, forneceu bom rendimento do antígeno para a realização de cada teste, na cavidade da placa $(0, \mathrm{lug})$, tendo $\mathrm{cm}$ vista os protocolos utilizados na sensibilização das hemácias e na execução do teste IIAC.

Quanto ì reprodulibilidade $\mathrm{em} 20$ diferenles lotes de reagentes de hemícias, houve um desvio-padrão dentro do limile de aceitação previamente determinada com regente de bom descmpenho.

Este teste pode scr aplicado na captura de imunoglobulinas de outras classes, após modificações, bcm como cm amostras de soro, com vantagens tcóricals quanto à scnsibilidade $\mathrm{cm}$ relação a reação de hemaglutinação passiva. A sensibilidade do teste EI $\Lambda$ C para anticorpos específicos anti-cisticercos de Taenia solium, da classe IgG, no I.CR foi de 81,5\%. Portanto, o lestc foi capar de demonstrar anticorpos específicos anti-cisticcrcos de Taenia solium da classc IgC $\mathrm{cm} 8,5 \%$ clos pacientes com nourocisticercosc estudados. $\Lambda$ especificidade foi de 95,3\%, portanto o teste apresentou negaltividade para anticorpos da classe Ig (r cm $95,3 \%$ das amostras do grupo controle. Istes índices de descmpenho, aliados à reprodutibilidade do teste cà estabiliclacle do reagente, além da cxecução simples c o alto rendimento levam a considerá-lo como uma altcrnativa no diagnóstico da neurocisticcrcose, e com possível aplicação $\mathrm{cm}$ inquéritos sorocpiclemiológicos $\mathrm{em}$ laboratórios de saúcle pública.

PLAIARISSI, C.S, de M. \& NITRINI, S.M.O. de O. [Capture erytroimmunoadsorption test for neurocysticercosis immunodiagnosis]. Rev. Saúde Pública, 28: 116-20, 1994. The capturc erytroimmunoadsorption (C-EIA) test was standardized for detection of Taenia solium cysticcreus-IgG specific antibodies in cerebrospinal fluicl (CSIF) from paticnts with ncurocysticcreosis. For the C-liIA test perlormance a reagent for specific antibody detection was prepared using sheep's red blood cells (SRBC) in a concentration of $0.25 \%$ sensilized with crude saline extract antigen (SEA) obtained fiom Cysticercus cellulosae. The optimum concentration of $S \mathrm{~S} A$ for SRIBC sensitization was foug/ml. The yicld of SFA was 0.1 lug protein/cavity. Whan 58 CSF samples from patients with neurocysticercosis were analysed the sensitivity of the test was found to be $84.5 \%$ and the confidence limit of $95 \%$ probability (C. $95 \%$ ) ringed from $75 \%$ to $94 \%$. The specilicity was $95.3 \%$ (CI. $95 \%$ from $90.7 \%$ to $99.9 \%$ ) when CSl samples from the control group were analysed. 'The C-EIA test was shown to be efficient for neurocysticercosis diagnosis and important for public health laboratories, because of its low cost, high reagent yicld and case of use. 
Keywords: Cysticercosis, diagnosis. Immunosorbent techniques. Antibodies, helminth, cerebrospinal fluid.

\section{Referências Bibliográficas}

1. BASSI, G.E., CAMARGO, M.E., BITTENCOURT, J.M.T.; GUARNIERI, D.B. Reação de imunonuorescência com antígenos de Cysticercus cellulosae no líquido cefalorraquidiano. Neurobiologia, 42:165-70, 1979.

2. BLAGI, F., NAVARRETE, F.; PINA, A.; SANTIAGO, A.M.; TAPIA, L. Estudio de tres renciones scrologicas en el diagnóstico de la cisticercosis. Rev. Med. Ilosp. Gerah México, 25:501-8, 1961.

3. BING, D.H.; WEYANG, J.G.M.; STAVITSKY, A.B. Hemagglutination with aldeyde-fixed erythrocytes for assay of antigen and antibodies. Proc. Soc. Exp. Biol. Med., 124:1166-70, 1967.

4. BONAMETTI, A.M.; BASILE, M.A.; VAZ, A.Z.; BAI.DY, J.L.S.; TAKIG UTI, C.K. Indice de positividade da reação imunoenzimática (ELISA) para cisticercose no líquido cefalorraquidiano e no soro de pacientes com epilepsia. Rev. Inst. Med. Trop. São Paulo, 34:451-8, 1992.

5. BRADFORD, M.M. A rapid and sensitive method for the quantitation of microgam quantitics of protein utilizing the principle of protein-dye binding. Anal. Biochem., 72:248-54, 1976.

6. COSTA, J.M. Teste imunoenzimático (ELISA) no diagnóstico da ncurocisticercose. São Paulo, 1983. [Tese de Doutondo - Instituto de Ciências Biomédicas da USP].

7. GALEN, R.S. \& GAMBINO, S.R. Beyond normality: the predictive value and efficiency of medical diagnosis. New York, John Wiley \& Sons, 1975.

8. HOSHINO-SIIIMIZU, S.; NAGASSE-SUGAHARA, T.K.; CASTILHO, E.A.; CAMARGO, M.E.; SIIIMIZU, T. Diagrama de verificación para evaluar reactivos de hemaglutination usidos en el diagnostico de la enfermedad de Chagas. Bol. Oficina. Sanit. Panam., 101:465-76, 1986.

9. IMAI, M.; YAMASIIITA, Y.; MIYAKAWA, Y.; MAYUMI, $M$. Haemagglutination inhibition assay of the common determinants and subspecificities of Australia antigen. Immunology, 27:871-8, 1974.

10. MACHADO, A.J.; CAMARGO, M.E.; HOSIIINO, S. Reação de imunofluorescência para a cisticercose com particulas de Cysticercus cellulosae fixadas a lâmi- nas de microscopia. Rev. Soc. Bras. Med. Trop., 7:181-3, 1973.

11. PAUL, J.R. \& WIITE, C., ed. Serological epidemiology. New York, Academic Press, 1973.

12. PIAL.ARISSI, C.S.M.; VAZ, A.J.; SOUZA, A.M.C.; NAKAMURA, P.M.; CAMARGO, E.D.; SILVA, M.V.; UEDA, M. Estudo comparativo de testes sorológicos no diagnóstico imunológico da ncurocisticercose. Rev. Inst. Med. 7'rop. São Paulo, 29:367-73, 1987.

13. SIEGEL, S. Estatística não paramétrica. São Paulo, McGraw-Ilill, 1981.

14. SO'TELO, J.; GULRRERO, V.; RUBIO, F. Neurocysticercosis: a new classification based on active and inactive forms. A study of 753 cascs. Arch. Intern. Med., 145: 142-5, 1985.

15. UEDA, M.; NAKAMURA, P.M.; WALDMAN, E.A.; CHIEFII, P.P.; SOUZA, A.M.C.; SPIR, M.; GERBI, L.J. Frequência de anticorpos anti-Cysticercus cellulosae $\mathrm{cm}$ população de risco para cisticercose e em segmento de população considcrado supostamente normal $\mathrm{cm}$ regiões do estado de São Paulo, Brasil. Rev. Inst. Aclolfo Lutz, 44:25-8, 1984.

16. UEDA, M. Sífilis associada ou não a Sindrome da Imuno deficiência Adquirida (AIDS): padronização do teste de eritroimunoadsorçĩo por captura e detecção de anticorpos IgM c Ig A anti-Treponema pallidum nas diferentes formas da doença sililitica. São Paulo, 1988. [Tese de Doutorado-Instituto de Ciências Biomédicas da USP].

17. VAZ, A.J. \& FERREIRA, A.W. Imunodiagnóstico da neurocisticcrcose: teste imunocnzimático com antígenos quimicamente ligados a suportes para a pesquisa de anticorpos em soro e líquido cefalorraquidiano. Rev. Med. Tiop. São Paulo, 30:1-10, 1988.

18. VAZ, A.J.; ILANASIIIRO, A.S.G.; CIIIEFFI, P.P.; FERREI$\mathrm{R} \Lambda, \mathrm{A}$.W. Frequência de individuos com anticorpos séricos anti-Cisficerctus cellulosae em cinco municipios do Estado de São Paulo. Rev. Soc. Bras. Med. Trop., 23:97-9, 1990.

19. VIANNA, L.G.; MACEDO, V.; COSTA, J.M.; MELLO, P.; SOUZA, D. Estudo sorocpidemiológico da cisticercose humina em Brasília, Distrito Federal. Rev. Soc. Bras. Med. Trop., 199:149-56, 1986.

Recebiclo para publicação em 2.8.1993 Reapresentado em 23.11.1993 Aprovado para publicação em 31.1.1994 